\title{
Archives, Documentation and Ethnomusicology in Nigeria
}

\author{
Folorunso David Jayeola, Olusola Samuel Akintunde and Anuli Francisca \\ Ugwu
}

Department of Music, Alex-Ekwueme Federal University Ndufu-Alike, Ikwo

jayeolafolorunso@gmail.com

\begin{abstract}
Most African heritage and national values seem to have lost their originality to modernization, especially in Nigeria. Not only in the field of music, but also in every other arts and humanities. One of the "biggest" problems most Nigerian scholars face today is the problem of archiving and documentation. This has contributed greatly to the poor and watery research output in Nigeria. Historically, from Pre-colonial era to post-colonial era, Nigeria music has suffered from poor archives, documentation due to lack of proper education on archives and documentation. Improper or poor knowledge of archives and documentation thereby, has caused a great loss of some of our musical cultural values during the process of modification. Proper archiving and documentation help to give memory of what has happened in the past for proper and future development $/$ progress. Its knowledge system is inevitable. The ethnomusicologist is known globally for scientific researches on how and why of any musical practices, therefore, will have to play a significant role in putting proper system of archiving and documentation of musical practices in Nigeria. On this note this research helps to expose, with scientific details, the roles of ethnomusicology in improving the knowledge system of archives and documentation of music practices in Nigeria.
\end{abstract}

Keywords-Archive, Documentation, Ethnomusicology and National Values.

\section{INTRODUCTION}

Since the beginning of human race, music, like every other art has begun to experience great modification and poor documentation which has led to extinction of many indigenous music and other arts. Alex (2015), expresses his mind on the state of many Africans towards proper archiving. "Most Africans don't know their history and have little or nothing to say respect to their place of birth or state of origin". However, the advent of science and technology in the global village, has contributed to the culture of archiving and documentation in every sphere of arts and sciences, with no limitation of any area of human life. Through this development it was obvious that the archiving / documentation or preservation was not done only by the academics but also by other agencies in the community.

In Africa, the music of Africa has gone through processes, development, modification, alteration, etc. This can be traced from the precolonial to colonial and post-colonial where we presently live. Foremost among those who led the race for preserving and studying African music was Devonshire-born Hugh Tracey. Tracey began taking an interest in African music in 1921, during his early days in Zimbabwe, where he had come to farm tobacco with his brother. Living with the Karanga people in Zimbabwe,
Tracey was immediately convinced of the importance of music in the lives of the people. This was despite the dismissive attitude of the colonial settler community in the area. He relates his experience as follows:

"The history of this collection of authentic African music, songs, legends and stories is in many ways a personal one. It dates back to the early 1920s when I first sang and wrote down the words of African songs. I heard in the tobacco fields of Southern Rhodesia. Several years later (1929), I made a number of discs with a visiting recording company (Columbia, London) when I took 14 young Karanga men with me to record in Johannesburg, 500 miles south. These were the first items of indigenous Rhodesian music to be recorded and published. Shortly afterwards, several of these items were used by John Hammond of CBS at Carnegie Hall in New York as preliminary music to his program on the historic occasion when he presented on the stage, for the first time in that city, the music and the 
personnel of a number of southern Negro bands."

From Tracey's recollection, it becomes clear that the collection and archiving of music in Africa was not only an academic exercise but was strongly linked with commercial interests of recording companies.

What then is the state of archives, documentation or preservation in the contemporary Africa, in particular Nigeria? What are the problems and how do we encourage the culture of good archive and documentation for future prosperity?

\section{Documentation}

In the discussion of what documentation is and what it's not, for the clearer understanding of its knowledge and for proper usage, therefore, it is very necessary to pound on definition of documentation as stated by Oxford Advance learner's dictionary:

According to Oxford Advance Learners dictionary, documentation is stated as "the process of classifying and annotating texts, photographs, etc". Analyses on the definition gives a basis knowledge of what documentation should be and what it should not be. It is a process, where oral information, writing documents, pictorial document, etc, are received for record purposes. This include the date, day, year of the event or information received. Now there are some technical questions ethnomusicology scholars consistently asked, such as: What event or activities should be documented / What type of documentation should be given scholarly approach?

One of the habit or spirit that hinder proper documentation / impact factor documentation is self-bias towards event or activities to be documented. The essence of documentation is to keep history, and therefore every event or activities is required to be given accurate attention for proper documentation. The good thing about what we've explored is that scholarly approach towards documentation practices are relatively easy to improve because the report is usually the result of the field.

\section{Archive}

At a completion of a proper documentation is archiving. According to Oxford Advance learner's dictionary, defined archive as "the place where historical documents or records are kept. A collection of historical documents or records providing information about a place, institution, or group of people. A well structure archive is where scholars go to access knowledge of the past and present for the progress, continuity, or authenticity of the ongoing research. A well structure archived is sectionalized for easy access with index of the available materials.

\section{EVENT / ACTIVITIES $\longrightarrow$ DOCUMENTATION $\longrightarrow$ ARCHIVE}

\section{Chat showing the process towards archive.}

The process of archiving musical activities / recordings in Africa research has not always been given a necessary attention, especially the traditional music. In spite the efforts of scholars such as J.H.K Nketia, Hugh Tracy, etc, efforts towards standard documentation and archiving are still insignificant most especially in Nigeria, where we have various traditional ethnic group, and which gradually are going on extinction. Nketia (2000), made it known that "there is nevertheless a growing accumulation of field recording in Africa itself that could form the nucleus of archives in individual African countries. They include private collections, recording at broadcasting and television stations, Ministries of Tourism, culture and Information, museums and academic institutions". He Nketia was able to point it out out on how African itself can form a functioning archiving in individual countries, with every other sector. He furthermore gives three main sections for proper archiving, as the private, institution and public archives.
"Private Archives: Archives not normally open to the general public, such as the archives of corporations (broadcasting, televisions and film corporations). Most time such archives can be found in private homes of individuals who can maintain it and for the benefit of the closed family.

Institutional Archives: Archives administered as units within research institutions, arts centers and museums and which may grow out of the scholars or a collector associated with the institution and the contributions of other scholars and field collectors who share a collective vision. Most time institutional archive are seen as public archive center or unit but with limitation to specific group of people

Public Archives: Archives that emerge through an administrative mechanism for bringing together scattered collections in private custody that are donated or acquired, holdings in Ministries and Department as well as in other public institutions". 
Viewing from the present state of Nigeria and its knowledge towards proper and standard documentation and arching, it is premature. In the Western hemisphere where there is a long tradition of libraries and archives which are constantly used by scholars and the general public, the creation and development of public archives of recording make sense, particularly where there is laws of a country make it compulsory for copies of published recordings to be places in a designated depository. The situation in many African countries does not warrant the creation of this kind of facility at the moment.Materials in private and institutional archives, on the other hand, are constantly used as reference and programme materials and their proper development and management need to be given attention.

\section{The Bane of Documentary}

Globally, there are agencies (private and government), whose responsibilities and practices are to document events and give it a proper archive for future references. Their roles and practice styles are stated for proper guidance of the user and this has helped may of the leading countries of the world. In Nigeria, the role of documenting and archiving traditional musical practices basically resides in the purview of the following government and private institutions/agencies/establishment:

a. Universities (Creative Arts/Music Departments)

b. Ministry of Arts and Culture (Federal and State)

c. Media Houses (Private and Government owned)

d. Libraries (National \& State)

e. Private Archives

However, a lot of factors have been identified as impediments responsible for proper documentation and archiving of in Nigeria. Some of the factors include but not limited to:

\section{Corruption:}

Publication on taxonomy of corruption (2018), stated that 'corruption is the single greatest obstacle preventing Nigeria from archiving its enormous potentials.

Corruption has eating deeply into the fabrics of many of Nigerian government parastatals and agencies. Most offices are been directed and controlled by unqualified personnel due to corruption, whereas, very many qualified personnel are not given the opportunity to contribute to the growth and development of Nigeria especially in places where good knowledge of archiving and documentation is needed. Recruitment is solely for gratification by the political class.

\section{Poor Knowledge of History}

The historical background of any society is or a group is never a joking matter. Any serious country does not take the place of her History for granted. It preserves, cherishes and showcases it to the world at every given opportunity. Every individual is expected to know basic historical knowledge of his country. In Nigeria, there is poor knowledge of history which has contributed immensely to the problem of documenting and archiving. Many documented materials could not be properly kept because persons it fell into their hands do not know the value of such material(s). The problem is more compounded as the study of History as a subject has been expunged from the senior secondary school curriculum. This has posed a problem of knowing anything about our culture. Knowing fully well that you cannot appreciate what you do not know.

\section{Poor Knowledge of Record Management}

Record management does not solely apply to administrative/bureaucratic establishment/ management circle. It can be applied to other disciplines and spheres of life. According to Sherii Lawson (n.d),

Record management is the system used to control an organisation's records from the creation of the record until it is achieved or destroyed. (Its) process is comprised of identifying records, classifying records, and storing records, as well as coordinating internal and external access. (https://study.com/academy/lesson/recordsmanagement-process-in-organisations.html).

Record management in the sense of this paper means taking note of musical events, documenting, archiving and creating a smooth medium of accessing such for reference purpose. Majority of personnel in charge of archives in Nigeria have poor knowledge of record and information management. This has resulted in non-documenting, damage and misplacement of vital historical musical practices which would have contributed immensely to appreciating our culture and musical practices better.

\section{Poor Technological Know-how}

Globally, very many activities or events have been taken over by technology, which documentation and archiving is not left behind. Developed countries of the world have embraced the use of technological tools in managing different aspect of human lives including documenting and archiving of any category of information. Nigeria as a nation is lagging behind in this respect. And this cut across all facets of her life.

\section{Lack of Funds}

Most of the agencies listed above as being responsible for researching, documenting and archiving traditional musical practices/creative practices are poorly funded. 
Many of them do not have basic tools/equipments such as Tape Recorder and Video Camera to carry out their field work. In the exception of private media houses who embark on pockets of documentation and archiving traditional Nigerian musical practices. This they do base on sponsorship/commercial purposes or they are commissioned to do so.

\section{Migration}

Migration is another problem facing documentation of the rich cultural heritage of Nigerians. Cultural music can mostly be found in the hinterland, however, due to economic factor, the custodians of this music moves or are moving to the city to seek for a means of livelihood. In the process, our cultural heritage got eroded.

\section{Religion}

Nigerians are very religious. This disposition has made them to look at any cultural or traditional music/activities as fetish. And for them to get involved in such activities is an act of committing sin. Individuals who are involved in this type of music tend to become indifferent immediately they become a devoted church attendee. Hence, persons who are supposed to serve as resource persons during research and documentation are reluctant or not interested in divulging useful information to the researcher due to their erroneous belief that it is a sin. This situation is not far from the assertion of "earliest ethnomusicologists who came to Africa to research into our indigenous music to formulate misleading theories and propagate false information about the music of Africa" (Aniedi, 2011, p. 113)

\section{Time}

Researching and documenting traditional musical practices can be time consuming. Most of this musical practices are seasonal. To get them recorded might take days/weeks because there are steps, processes and procedures which cannot be broken/interrupted of jumped due to our belief system. It takes a lot patience and diligence on the part of the researcher to get a full documentation of some of these musical practices. The researcher might have to spend some time in the hinterland to get details of an event under harsh weather condition. Most researchers do not have the wherewithal to embark on such venture.

\section{The Panacea to Documenting and Archiving Problems}

The solutions to the problems identified above are:

1. Awareness - Awareness should be created among Nigerians on the importance of knowledge of history. This awareness should start with school children of all ages to professionals in industries. This will inculcate and enhance the culture of documenting events and archiving of same. Going about this, Adedeji, (2016) suggested that "this can come in terms of seminars and workshop and most importantly incorporating it within the school curriculum in tertiary institutions ...' (p. 267).

2. Technology - It is necessary we move with time in order not to be left out. There is need to employ technological tools in keeping information to curb loss or damage of vital documented facts. We are in the e-world, ICT should be adopted in collection, processing, storing and disseminating information on Nigerian musical practices.

3. Improved Funding - Government at all level and concerned citizens should improve funding for researches into Nigerian musical practices in order to have them documented and archived for future use. There is need for 'intervention of financial institutions in Nigeria through investment in the industry to give it a boost the same way some ailing banks were saved through the central bank's intervention in Nigeria' (Adedeji, 2016: 267).

\section{Process of Documentation in Ethnomusicology}

The following guidelines below provide practical insights into the process of conducting a level field documentation project. These guides cover essential topics such as project planning, research ethics from the perspectives of the fields of folklore, ethnomusicology, museum studies and intellectual property of policies. Other methods of documentation includes: interviewing tips and techniques, writing field notes

(A) Interviewing Guide: An interview is more than following a list of pre formulated questions depending on your instinct, empathy or specialized knowledge of community history in order to obtain good answers. Importantly, it is matter of respectful and interested listening, letting the story unfold, and paying close attention to the verbal and nonverbal cues that signal the speakers own interest and sense of importance of the topic under discussion. Altogether, these will enable you to understand from the perspective of individuals, the everyday activities, cultural traditions and artistic performance that structure and enrich community life.

(B) Field Notes: a record of the researcher's activities in the field includes general observations about the progress of field work, impressions of interviewers, summaries of conversations, descriptions of the natural and built environment and drawing diagram of buildings. At the very least, field note provide a useful chronology of the field worker's activities. At best, they are the intellectual core of a project's documentation, 
preserving the observations and ruminations of the field worker as the project unfold.

(C) Collections Appraisal and Description: These documents cover a range of activities in the area of collections, processing and acquisition, such as written assessments and appraisals of potential acquisitions. Another central activity of repository staff is processing and describing the content of collections once they are housed in the institution's archive. The document provides both simple catalogue schema for cataloging oral history interviews.

(D) Interview Log: Under this, the logs are concise, written summaries of recorded interviews. They are not as extensive as the verbatim transcript but are more substantial than the quickly jotted field notes taken. It is an important means of providing yourself colleagues with key understandings of the subject matter, themes and perspectives contained in an audio or video recording of community members.

(E) Permission and Release Forms: under this, the consent of the individuals who share their stories and knowledge with you during the course of documentation should be obtained. This is because, it is an essential practical responsibility. Some of the sample form which have been used in fieldwork projects, may as well be adapted for use in one's own research.

\section{CONCLUSION}

This research is an ethnomusicology research that has given an exposition on the place of archiving and documentation in Nigeria. In the cause of the write up, the researchers were able to give a brief historical background of ethnomusicology and in relation globally. In addition, was the bane of documentation and the panacea to documenting and archiving problems which was given a scholarly approach in the research? It is pertinent to note that documenting and archiving musical practices is a very important aspect of musicology which should be given attention. Aside being a means to promote our culture, it can also be a source of revenue for organisations and the country at large. It will also simplify the process of advanced of studies/research in Nigerian musical practices. Whereby, a database is created where researchers can have access to materials and information on a particular music. However, it is believed that if the suggested solutions proffered above are adhered to, the country Nigeria stands to benefit greatly from this aspect of musical venture.

\section{REFERENCES}

[1] Adedeji, W. (2016). The Nigerian music Industry: Challenges, Prospect and Possiblities. International Journal of Recent Research in Social Sciences and Humanities (IJRRSSH). 3, 1. 261-271.

[2] Alex, M. (20015). The Africans and History: A pocket book on my personal observation of African culture. Boudeaux Press. Boudeaux.Pg. 5.

[3] Aniedi, E. E. (2011). MekiNzewi and the African Voice in Ethnomusicology. In Y. S. Onyiuke, I. O. Idamoyibo\& D. C. C. Agu (Eds.), Meki and the Musical Arts of Africa: A book ofgeneral reading in honour of Professor MekiNzewi. 113-116, Nimo: Rex Charles \& Patrick Ltd.

[4] Nketia, J.H. (2000). Recording and Dissemination of Traditional Music. "Rethinking African Arts and Culture". A book edited by Dele Layiwola. Centre for Advance Studies of African Society (CASAS). Series 4.pg. 55

[5] Nkketia, J.H (1980). African music and Western praxis: A review of Western perspective on African musicology. Canadian Journal of African Studies. Pg.

[6] Oxford Advance Learner's Dictionary $9^{\text {th }}$ Edition: de Oxford University Press 2017

[7] https://www.lorman.com/resources/the-importanceof-proper-documentation-procedures-15189. Accessed May 10, 2019.

[8] www.carnegieendowment.org/2018/07/17.newtaxonomy-for-corruption-in-nigeria-pub-76811 (Accessed on Sept. 27, 2019).

[9] https://study.com/academy/lesson/recordsmanagement-process-in-organisations.html (Accessed on Sept. 27, 2019). 